catalogue, Dr. H. Forster Morley, 34-35, Southamptonstreet, Strand, London, W.C.

I am, Sirs, yours faithfully,

King's College, London, March 4th, 1901.

$$
\text { W. D. Halliburton. }
$$

\section{THE RECENT HUNTERIAN URATION : THE EVOLUTION OF MAN.}

To the Editors of THE LANCET.

SIRs,-Possibly you may find space to allow me to mention one or two difficulties which crop up in perusing the markedly - interesting and important details brought forward in this year's Hunterian Oration ${ }^{1}$ touching the origin of the human race and the sources and physical characteristics of the Earopean sections; and I ask light not so much in regard to what we now are as whence and how we came to be man.

Assuming that man and the apes are derived from an identical or kindred stock, if I understand Mr. Macnamara aright his view is that the departure of the one branch from the common stock leading to man with his vast intellectual predominance over the other primates was rendered possible by a retarded closure of the frontal sutures permitting of the anterior brain growth and evolution, while in the anthropoid apes the sutures continued to close early in life, "the anterior part of their brain not increasing beyond the size it had attained at the end of the first year," and the explanation of this imperfect evolution of their frontal lobes lying to a large extent in " the premature ossification of that part of the skull which encloses the forebrain." But granting that the line of structural changes was such, does not a more important question lie behind it, to the originaling and guiding force which rendered possible this divergence from the hitherto prevailing rule? At the time at which these two sections of higher animal life commenced to diverge presumably the skull features in the one closely approximated those in the others; presumably the change was not accidentally brought about, nor by abnormal divergence, but by a gradual physiological process not common to the whole stock but limited to the one section and not potential then or at any subsequent period in the anthropoid apes; what, then, was the intrinsic power or extrinsic conditions which brought about the structural change which permitted the one section to advance to man and the absence of which retained the apes in the lower stage of being?

An innate faculty to respond to external natural demands, and an environment necessitating an increased brain and higher function of an intellectual character and the organ responding thereto, provide an apparently rational explanation, bu; to permit of it the bony cranium must accommodate itself to the altered brain conformation, either by accident or in physiological response to it. But, apparently, the view taken by Mr. Macnamara, while admitting an innate power of the brain "to develop and so meet the increased demand arising out of the struggle for existence," is that "the factors governing the growth of the skull differ from those which develop the brain" the brain not being dominant in the ontcome, though the marked correspondence during the subsequent evolutionary steps of the human race between the osseous protection and the protected viscus indicate at least a clear coördinating power correlating both in structural advances if not an actual controlling influence of the brain in the skull conformation arrived at. Yet if this non-closure of the sutures in the man section of the primates is not to be found in an advancing brain organism, the osseous framework developing on lines independent of it, wherein lies the explanation of the anterior part of the anthropoid ape skull remaining a shut box controlling the size and function of its brain while that of man has been permitted gradually to expand in conformity to an enlarging viscus not only endowed with higher intellectual powers, but with an additional speech faculty? Why the poor ape has been handicapped by the continuance of this common original structural defect which has clung to him ever since despite his surroundings, while man was freed from it and allowed to progress, is a mystery ; nor is it easy to understand why, assuming that the line of progress has laid through a struggle for existence, the anthropoid apes escaped this struggle at the time when it operated to the advantage of the buman family or since, or assuming that they have since been subjected to its influence why the same sequence of events has not again followed in their case as originally in man.

There is yet another point. The race of mar has sincedeveloped two distinct cranial divergencies in altered relation of length and breadth, carrying with them corresponding brain peculiarities-dolichocephalic and brachycephalic. What relation do these bear to the original change? which was the dominant factor in the result-brain or craniom? and what was the cause in operation?

I write solely with the view of hoping to get cleared up knotty points in the chain of evolution of man, not as throwing any doubts on his probably common physical source with the lower primate order; to some it may suffice to know that he " is what he is," but to others the gradually unravelling past may be pregnant with hope touching his. future; and among these latter I enrol myself.

I am, Sirs, yours faithfully, Francis H. WELCH, F.R.O.S. Eng. Surgeon-Colonel (retired), M.S.

Brandram-road, Blackheath, Feb. 25th, 1901

\section{PREGNANCY AND LABOUR COMPLICATED} BY OVARIAN TUMOURS.

\section{To the Editors of THE LANCET.}

SIRs,-The valuable lecture on pregnancy and labour complicated with ovarian tumours by Mr. J. BlandSutton published in THE LANCET of Feb. 9th (p. 382), will serve the useful purpose of directing attention to an important subject which has been hitherto much neglected in the obstetric literature of this country. While in general agreement with the opinions he expresses and more especially as to the superiority of ovariotomy in labour where that is possible, I must take exception to his denunciation of reposition as a means of treatment. He characterises it as a measure "decidedly in opposition to all the canons of surgery." He founds this dictum on the two-fold proposition that "pregnancy exerts a baneful influence on ovarian tumours, and ovarian tumours are, as a rule, inimical to successful pregnancy." These reasons, though perfectly valid in regard to operation during pregnancy, are, it seems to me, irrelevant where an ovarian tumour blocks the pelvis during labour. It will naturally suggest itself at the outset that a woman in labour with an ovarian tumour in the pelvis presents an obstetrical rather than a surgical problem. In comparatively few of the published cases where reposition was effected would the circumstances have permitted the services of a skilled operator to be called in. Experience thus bears out the observation of Playfair that it is only exceptionally that expert attendance, with all the necessary appliances, can be had.

The great danger in these cases is delay, to which much of the mortality arising from this complication is to be attributed. This danger is well illustrated in the case which Mr. Bland.Sutton himself cites where, from the firm impaction of the head, it was found necessary to perform Cæsarean section before the tumour could be brought out of the pelvis. It will not be denied that this must add to the dangers of ovariotomy. Whether reposition was attempted earlier in labour is not stated.

On a priori grounds it would seem that to push the tumour out of the pelvis is a procedure comparatively free from danger and calculated to give immediate obstetric results quite as good as ovariotomy undertaken in unsuitable surroundings. A posteriori evidence confirms this view. In 41 cases in which reposition was accomplished six deaths followed, but three only can be fairly attributed to reposition, that is a mortality of 6.9 per cent. It is true that of several cases of ovariotomy performed during labour all bave been successful, but all were performed by experienced operators and their numbers are still too few to justify dogmatic conclusions. A fairer means of comparison is to be found in the statistics which Dsirne has published of ovariotomy in pregnancy. Notwithstanding that the operations (135 in number) were in general undertaken under the most favourable conditions and with the strictest antiseptic precautions Dsirne found a maternal mortality of 5.9 per cent., little better than that obtained by reposition during the actual progress of labour.

I do not for a moment maintain that reposition is 
entirely free from danger, but to found on one unsuccessful case an unqualified condemnation of a metbod which in the past has given such good results can scarcely be regarded as fair; indeed, the case which Mr. Bland-Sutton cites is, so far as I know, the sole published-instance in which axial rotation followed reposition, with the doubtful exception of a case reported by Camden. Even should complications arise after delivery, though they do not seem to be more conmon in pelvic tumours that have been reposed than in the case of abdominal tumours, the statistics of post-partum ovariotomy show that they may be dealt with by operation with every prospect of success. Where, as must often happen, circumstances do not allow of immediate ovariotomy reposition is without doubt the best method of dealing with this dangerous complication of labour, as I have elsewhere shown, ${ }^{1}$ and it will, I am convinced, continue to obtain the sanction of the most advanced obstetric authorities. It would, indeed, be as unreasonable to expect the general practitioner, under whose care most of the cases come, to advise an ovariotomy, which would involve dangerous delay, and expect him to advocate immediate operation in a case of strangulated hernia without first attempting reduction.

I am, Sirs, yours faithfully,

Aberdeen, Feb. 25tb, 1901.

R. G. MCKerRoN.

\section{"RETURN" CASES OF SCARLET FEVER: A SUGGESTION.}

To the Editnrs of THE LANCET.

SiRs, - In THE LanceT of Feb. 23rd, p. 576, you referred to the recommendations made by the Royal College of Physicians of London to the Metropolitan Asylums Board that experiments should be made with a view to ascertaining in what way the tendency of patients to carry home infection from hospital can best be overcome. The suggested experiments are in the direction of a much greater classification of patients than has bitherto been practised, as regards the separation of complicated from uncomplicated cases, and of the complete isolation of cases for a short time prior to their leaving hospital. In view of the not very satisfactory results which, as recent statistics have shown, the hospital treatment of patients on the aggregation system has hitherto yielded, everyone, I think, will welcome any attempt to ascertain whether or not the methods hitherto practised are really the best. May I venture to suggest that the proposed experiment might with great advantage be carried further? Would it not be possible, in one or more of the hospitals of the Metropolitan Asylums Board, to set apart a considerable number of isolation wards (specially built for the purpose if necessary) for the separate treatment of patients or families of patients during the whole course of their stay in hospital-in other words, to try the effect of substituting true isolation for aggregation? There is reason to think, judging from the remarkable experience of towns where patients are treated in their own homes, that with such a method the percentage of septic complications would be lessened, the number of return cases reduced, and the patients could be allowed to return home very much sooner than is at present the case. I am, Sirs, yours faithfully, C. Killick MillaRd.

Town Hall, Burton-upon-Trent, March 1st, 1901.

\section{CAMBRIDGE APPOINTMENTS ASSOCIATION.}

To the Editors of THE LANCET.

SIRS, - - It will be a great kindness if you will once more draw the attention of qualified medical men who are graduates of the University of Cambridge to the Cambridge Appointments Association. We have an increasing number of applications for medical men to act in various capacities and would very gladly be of service to Cambridge practitioners who have the requisite qualifications. The amount of the subscription to this association ( $5 s$. per annum) is not large and no commission is charged in respect of appointments given or received. We have, therefore, no hesitation in asking Cambridge men who are qualified to join the association in order that we may extend its operations in the medical world. What is lacking at present is not appointments but men to recommend for them. We are in need particularly of those who have had special training in bacteriology as well as in other subjects, but we hope to be of service to others.

I am, Sirs, yours faithfully, W. A J. ARCHBOLD, Secretary.

73, Trumpington-street, Cambridge, March 1st, 1901.

\section{" LEGISLATION AGAINST NATIONAL INTEMPER ANCE."}

To the Editors of THH LANOET.

SIRs,- - Your able leading article on the above subject on Feb. 9th should lead the way to concerted action on the part of the profession by (l) the issuing of a largely and influentially signed statement pointing out in plain and truthful language the action on the organs of the body of excess in alcohol, particularly when taken in the form of spirit; and (2) the determination of each subscriber to the document to use his influence with his patients in correcting the false ideas that are current with the public as to the remedial and dietetic value of alcohol. Bands of Hope do much good by teaching the young the wisdom of avoiding the snares of drink, and temperance societies are a sort of continuation school for the youtb as well as a means for reforming the drunkard, but the great mass of excessive drinkers are wholly untouched by these means. One of the greatest hindrances to true temperance is the virulent denunciation of the moderate drinker indulged in by some total abstainers. Intemperate speech will never promote temperance. By "moderate drinkers" I mean those who take habitually a moderate amount of light wine or beer with their meals and, as a rule, avoid spirits. If this standard were commonly followed there would not be one-tenth the present amount of drink consumed.

Very few people outside the medical profession have any idea of the havoc wrought by excessive drinking. The ordinary signs of excess are plain enough, but what the laity require instruction upon is the insidious and ever-increasing damage to the vital organs cansed by over indulgence, especially when it takes the form of constant nipping. These facts must be urged on patients, alike in the hospital and the consulting room. It may be said that a medical man has not the time to take on the rôle of a temperance reformer. My reply would be an appeal to the spirit of true patriotism The substitution of whisky for wine and malt liquors, which is so much the custom just now, is responsible for much of the chronic alcoholism so prevalent. The bugbears gout and rheumatism are a plausible excuse with many spirit-drinkers.

Societies, lectures, and addresses have had but little effect on the insobriety of the nation, and it is high time to adopt a man-to-man treatment, and the one to undertake it is the medical man. The late Professor Drummond has referred to the importance of individuals in carrying out great reforms as follows:-

The past has, indeed, no masses. Mran, not masses, have done all that is great in history, in science, and in religion. ...... We require to be taught again to-day to be content with aiming at units. Every atom in the universe can act upon every other atom, but only through the atom next it. And if a man would act upon every other man he can do so best by acting, one at the time, upon those beside him. The true worker's world is a unit. ...... Work with units, but above all work at units.

Weymouth-street, W., March 6th, 1901.

\section{"THE COVENTRY DISPENSARY." To the Editors of THW LANCET.}

SIRs,-That "the heads of the profession" are the men who stand in the way of reform is proved by the action of some of the Birmingham consultants. Had the consultants been true to the profession the resclution lately passed by the Birmingham and Midland Counties Branch of the British Medical Association would have been a gigantic step in reform, but consultants by continuing to meet in consultation the dispensary staff are obstructing reform in a most audacious manner. The Birmingham consultants professed a very high standard of ethics when their own pockets were assailed by the Birmingham Consultative Institution and when they were loyally supported by the general practitioner, but when the interests of general practitioners are assailed these consultants, instead of giving a helping hand, are found in the camp of the enemy-i.e., 